\title{
Net Thermal Radiation in the Atmosphere of Venus
}

\author{
H. E. REVERCOMB, L. A. SROMOVSKY, AND V. E. SUOMI \\ $034:$ \\ Space Science and Engineering Censer, University of Wisconsin, Madison, Wisconsin 53706
}

AND

R. W. BOESE

NASA-Ames Research Center, Space Science Division, Moffett Field, California 94035

Received June 2S, 1984; revised November 19, 1984

\begin{abstract}
The four entry probes of the Pioneer Venus mission measured the radiative net fux in the atmosphere of Venus at latitudes of $60 \% \mathrm{~N}, 31^{\circ} \mathrm{S}, 27 \mathrm{~S}$, and $4^{\circ} \mathrm{N}$. The three higher latitude probes carried instruments (small probe net thux radiometers; SNFR) with external sensors. The measured SNFR net fuxes are too laree below the clouds, but an error source and correction scheme have been found (H. E. Revercomb, L. A. Sromovsky, and V. E. Suomi, 1982, Icarus 52, 279-300). The near-equatorial probe carried an infrared radiometer (LIR) which viewed the atmosphere through a window in the probe. The LIR measurements are reasonable in the clouds, but increase to physically unreasonable levels shortly below the clouds. The probable error source and a correc. tion procedure are identified. Three main conclusions can be drawa from comparisons of the four corrected tux profiles with radiative transfer calculations: (1) thermal net nuxes for the sounder probe do not require a reduction in the Mode 3 number density as bas been suggested by $O$. $B$. Toon, B. Ragent, D. Colburn, J. Blamont, and C. Cot (1984, Icarus 57, 143-160), but the probe measurements as a whole are most consistent with a significantly reduced mode 3 contribution to the cloud opacity: (2) at all probe sites. the fluxes imply that the upper cloud contains a yet undetected source of IR opacity; and (3) beneath the clouds the fluxes at a given altitude increase with latitude, suggesting greater IR cooling below the clouds at high latitudes and water vapor mixing ntios of about 2-5 $\times 10^{-5}$ near $60,2-5 \times 10^{-4}$ near 30 , and $>5 \times 10^{-4}$ near the equator. The suggested latitudinal variation of IR cooling is consistent with descending motions at high latitudes. and it is speculated that it could provide an important additional drive for the general circulation. O leos Acadonic Press. be.
\end{abstract}

\section{INTRODUCTION}

All four probes of the Pioneer Venus Multiprobe Mission carried instruments to measure radiative net flux. Instruments on the three small probes (small probe net flux radiometers, SNFR) deployed external sensors to measure the total broadband net flux (Sromovsky et al., 1980; Suomi et al., 1980). Therefore, the SNFR measurements for the day probe, which entered the atmosphere at a solar zenith angle of $80^{\circ}$, included a small solar net flux contribution. For this paper, an estimate of the solar net flux at the day probe site has been subtracted from the measurements. The large (or sounder) probe instrument (large probe infrared radiometer, LIR) was completel enclosed inside the probe pressure vesse and measured the broadband thermal ne: flux (Boese et al., 1980). The LIR also mea sured the net flux in five narrow spectra bands with wavelengths between 4.5 and 1 : $\boldsymbol{\mu m}$.

Net radiative flux measurements can prc vide considerable information on the stat. of an atmosphere. The thermal net flux $i$ defined to be the upward infrared (IR) flu. minus the downward flux, implying that th change of the net flux with altitude is the If. cooling or heating at a given altitude Clearly, net fux measurements are directl related to atmospheric energy budgets an: to the energy transport by the circulation 
In addition, since the net flux is determined by the structure and composition of the atmosphere, radiative transfer modeling can yield constraints on what optically active trace constituents and cloud properties are consistent with flux measurements, if the temperature and the radiative properties of the major constituents are known.

The net flux measurements from two of the three Pioneer Venus small probes contained large errors below the clouds, and the measurements from the large probe were affected by an error which became significant a short distance below the cloud deck and grew to an extremely larze value at the surface. However, plausible explanations for the errors have been found and the corrected flux profiles have interesting implications. The corrected profiles are presented in the next section, and they are compared to thux profiles from radiative transfer calculations in Section 3. The implications of the measurements in the clouds where the corrections are relatively small follow in Section 4, Section 5 discusses the implication for the global distribution of water vapor and radiative cooling in the lower atmosphere, and the last section is a summary.

\section{CORRECTED NET FLUXES AND THEIR LIMITATIONS}

The basis for determining plausible estimates of the thermal net fux from the small probe SNFR measurements given in Revercomb et al. (1982) is summarized bere. In addition, a technique for correcting the large probe LIR thuxes is presented. The magnitudes of the corrections for both instruments are determined by forcing apreement with a range of calculated net tuxes at one altitude deep in the atmosphere. where the net flux must be small because of the large density of $\mathrm{CO}_{2}$.

\section{a. Small Probe Net Fluxes}

The small probe SNFR data and the range of corrected net fuxes are shown in Fig. 1. The data (indicated by the single

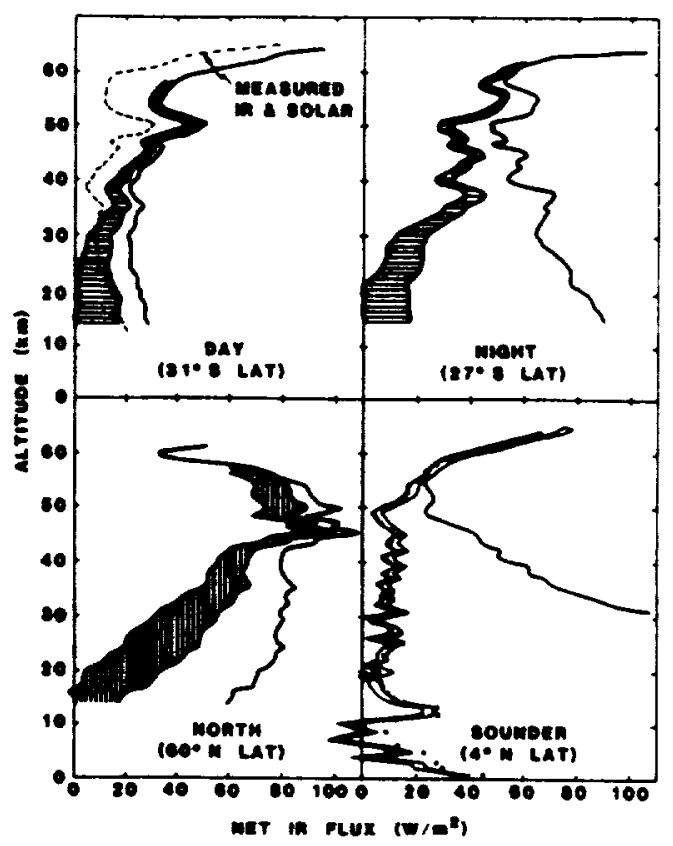

Fic. 1. Thermal net fux profiles from the four Pioneer Venus probes, sounder, day, night, and north. The solid curves in each quadrant of the figure show the measured thermal net tuxes. processed as if the instrument performance had been nominal. All of the measured tuxes have substantiv errors below the clouds. For the day, night, and north small probes the net fux radiometers (SNFR) were of identical desim. The regions fillod with parallel lines for these probes indicale the range of corrected tuxes. The dashed profile for the day probe is the total set tux profile. from which the thermal net flux was obtrined by accounting for the solar fux using the Pioneer Venus solar net fux (Tomasko et al., 1900a) adjusted to a solar zenith angle of $79.9^{\circ}$ (Suomi et al. 1980). The sounder, or large probe carried an infinared rediometer (LIR) with one broadband thermal channel and tive narrowband channels. The profile shown is for the broedband channel; the cotal data set was sampled at 1-tm intervals with no averaping. The measured oet fures below $30 \mathrm{~km}$ continued to increase to a clearly unreasonable value of $600 \mathrm{~W} / \mathrm{m}^{2}$ at the surface. The finer sotid curves for the sounder indicate corrected huxes, calculated assuming that the upward-boting feld of view was 3.5\% obstructed by an object with temperatures of 280 and $300 \mathrm{~K}$. The points are the corrections using the temperature of the instrument ambient blackbody for the obetruction.

continuous line) is uncorrected except for a repion of about $5 \mathrm{~km}$ immediately following sensor deployment, where the preheated sensor was much hotter than the atmo- 
sphere. The deployment transient correction is described in detail in Suomi et al. (1980). This correction decreased rapidly with time, reaching $10 \mathrm{~W} / \mathrm{m}^{2}$ near $58 \mathrm{~km}$ for the north probe and near $62 \mathrm{~km}$ for the day and night probes; the correction is negligible within 2 or $3 \mathrm{~km}$ of these altitudes. The external sensors on all three probes failed suddenly at about $13 \mathrm{~km}$, the same altitude where both the small and large probe temperature sensors and the LIR window heater failed. The data above $13 \mathrm{~km}$ seems to have been unaffected by the failure.

The major errors in the measurements occurred below the clouds. The night probe net flux reached $90 \mathrm{~W} / \mathrm{m}^{2}$ near $13 \mathrm{~km}$, which is slightly larger than that calculated for an atmosphere devoid of water vapor. Also, the decrease of the night probe flux with altitude would imply a large increase of IR opacity with altitude, which seems very unlikely in this cloud-free region.

The only known source of significant error for the SNFR has the right behavior to explain the apparently small errors in the clouds and large errors (especially for the night probe SNFR) below the clouds. The source of the error, discovered in laboratory testing after the mission, has been called the flow-through effect because a small flow of gas through the interior of the sensor head causes heat transport preferentially to the upwind side of the sensitive thermopile from other components of the sensor head assembly. This error was observed to have a strong dependence on the Reynolds number under the transient conditions of the laboratory tests.

To establish a model for the altitude dependence of the flow-through error during descent, we assume that the laboratory Reynolds number dependence also applies to the conditions of descent, where the sensor temperature was changing at a slowly varying rate (essentially equal to that of the atmosphere encountered by the sensor at most altitudes). Further it is assumed that the error is proportional to the temperature difference between the thermocouple and the other components of the sensor hear and that the internal gas flow is sufficienti, small that it does not influence the therm. couplings among the components making $L$ ? the head.

Under these assumptions, the corre : fluxes at all altitudes can be bounded if a bound to the correct flux is known at or 3 altitude. If the true net flux at $14 \mathrm{~km}$ is le: than the measured flux, the above assum] tions imply that the measured fluxes are uy per bounds to the true fluxes at all altitude: Further, if it is assumed that the true net flux at $14 \mathrm{~km}$ is less than $16 \mathrm{~W} / \mathrm{m}^{2}$ (see Sec 3, Figs. 4 to 7 ) and that the net flux shoul: never be negative deep in the atmosphere. the range of corrected fluxes is bounded $b$ the cross-hatched regions of Fig. 1 .

\section{b. Large Probe Net Fluxes}

The measured large probe LIR fluxes in creased rapidly from reasonable values i the clouds to extremely large, steadily in creasing values deep in the atmosphere The fluxes continue to increase below th lowest altitude where LIR data is shown i Fig. 1 to a clearly unphysical value at th. surface of about $600 \mathrm{~W} / \mathrm{m}^{2}$.

We present a phenomenological explana tion for the large LIR fluxes which assume that the instrument field of view to the at mosphere was different for upward anc downward viewing. Field-of-view asymme tries are sources of error to which instru ments measuring upward and downwarc fluxes independently are susceptible, anc the temperature dependence of the mea sured LIR net fluxes suggests that viewing asymmetries caused the LIR problems. Be low $45 \mathrm{~km}$ the variation of the fluxes witt atmospheric temperature $T$ is quite close tc $T^{4}$ (temperature is from Seiff et al., 1980) In fact, a function of the following form fit: the observed fluxes very well, except in the lowest few kilometers:

$$
E(T)=f \sigma\left(T^{4}-T_{i}^{4}\right),
$$

where $\sigma$ is the Stefan-Boltzmann constant $T_{i}$ is a temperature in the range of the inter. 
nal temperatures of the probe, and $f$ is a constant representing the fractional asymmetry of the upward and downward angular fields of view. The result of subtracting $E(T)$ from the measured fluxes is shown in Fig. 1 for a constant $T_{\mathrm{i}}=280$ and $300^{\circ} \mathrm{K}$. An amplitude of $f=0.035$ was chosen to make the residual fluxes physically reasonable. The amplitude is constrained to about \pm 0.001 by the assumption (used for SNFR corrections) that the flux at $14 \mathrm{~km}$ altitude is in the range 0-16 W/m (see Sect. 3). The flux error associated with this uncertainty decreases with increasing altitude and is less than $1 \mathrm{~W} / \mathrm{m}^{2}$ above $43 \mathrm{~km}$. The abrupt changes in the residual fluxes below $13 \mathrm{~km}$ are not physically reasonable and are probably associated with the failure of the external window heater near $13 \mathrm{~km}$.

An error of the form of $E(T)$ would result, for example, if there was a small obstruction of the upward-looking field of view of the instrument to the atmosphere by an object inside the probe. Then the measured down flux would be too small by $E(T)$ because the flux emitted from the low-temperature obstruction would replace the larger downward atmospheric flux. The atmosphere at the altitudes of interest here is sufficiently opaque that the downward flux is approximately equal to $\sigma T^{4}$. Therefore, deep in the atmosphere the net flux is much smaller than the up or down flux and even a small obstruction (like $3.5 \%$ of the angular field of view corresponding to $f=0.035$ ) can create large errors in the net flux. The use of the term "obstruction" is descriptive and is not meant to imply a specific mechanism. It is possible that the upwand-looking instrument light pipe was slightly out of alignment with the probe window, causing the window retainer to be viewed. An asymmetry between the stationary light pipes which direct the instrument fields of view upward and downward or misalignments of these pipes with the rotating light pipe are other possibilities (Boese et al., 1900). This generic explanation of the errors is supported by analyses of the errors of the narrowband channels which approximately obey Planck's law evaluated at the atmospheric temperature. The values for $f$ determined from these analyses were within $20 \%$ of that for the broadband channel. This explanation is also consistent with the normal behavior of onboard calibrations throughout descent. While it seems most likely that the source of asymmetry was not included in the optical train calibrated with the onboard blackbodies, no large increase in the calibration net fluxes would have been observed even if it had been. The maximum error from this source would have been about $3.5 \%$ because one of the two blackbodies were at ambient temperature.

Note that the small probe instruments are immune to this type of error. The SNFR instruments measure net flux directly, rather than differencing up and down fux measurements, and also. are flipped such that up- and down-facing sides are interchanged every second to prevent errors from up-down asymmetries).

The temperature of the obstruction must have been close to the probe interior temperature. For significantly higher temperatures, the correction would yield negative fluxes in the clouds. Therefore, an obstruction to the outside of the probe window is not a possible explanation. The temperature of the large probe forward shelf on which the LIR was mounted varied slowly during descent and stayed in the range from 280 to $300{ }^{\circ} \mathrm{K}$ throughout descent. The ambient blackbody temperature increased above the shelf temperature as the probe descended, but was less than $20^{\circ} \mathrm{K}$ hotter down to $15 \mathrm{~km}$. Fluxes corrected using $E(T)$ with $T_{i}$ given by the measured ambient blackbody temperatures are shown as individual points in Fig. 1. These points generally fall within the bounds set by the constant temperature corrections for 280 and $300^{\circ} \mathrm{K}$. It is apparent that the correction is not extremely sensitive to the temperature of the obstruction. When its temperature profile is within $\pm 20{ }^{\circ} \mathrm{K}$ of the ambient 
blackbody temperature, the corresponding uncertainty in the corrected fluxes is about $\pm 4 \mathrm{~W} / \mathrm{m}^{2}$

This approach for correcting the LIR fluxes seems to yield a surprisingly accurate correction to the measured fluxes, given the extremely large size of the error. We plan to further refine it, making more complete use of all available instrument data. More detailed explanations for the anomalies in the preliminary corrected fluxes below $13 \mathrm{~km}$ will be sought. It is expected, as suggested earlier, that failure of the window heater probably caused the perturbation near $13 \mathrm{~km}$, and further that the large residual flux at the surface was caused by a small increase of responsivity $(<10 \%)$ in the lowest $5 \mathrm{~km}$ where the detector tem. perature increased most rapidly (present analyses assume an altitude-independent responsivity). For these improved analyses, the simple model of Eq. (1) is generalized to include the effects of the $5-\mu \mathrm{m}$ absorption band of the LIR-type IIA diamond window, which can be significant at high temperatures when the window temperature deviates from atmospheric temperature. The error then takes the form

$$
\begin{gathered}
\left.E(T)=f_{\bar{\tau}-1} \int d \nu\left[\tau_{\nu}\left(B_{\nu}(T)-B_{\nu}\right) T_{\mathrm{i}}\right)\right) \\
\left.+\alpha_{\nu}\left(B_{\nu}\left(T_{\psi}\right)-B_{\nu}\left(T_{\mathrm{i}}\right)\right)\right] \\
\alpha_{\nu}=1-\tau_{\nu}-\rho_{\nu}
\end{gathered}
$$

where $B$ is the Planck radiance, $\nu$ is the wavenumber, $T_{w}$ is the window temperature, $\tau$ is the window transmittance, $\alpha$ is the window absorptance, $\rho$ is the window reflectance, and $\bar{\tau}$ is the mean window transmittance in the spectral regions contributing net flux. Equation (2) is accurately approximated by Eq. (1) when the atmospheric temperature is sufficiently low that its blackbody spectrum has little overlap with the absorptance spectrum of diamond. This refinement is not expected to have a significant effect on the basic results presented here: it is estimated to contribute about $1 \mathrm{~W} / \mathrm{m}^{2}$ at $45 \mathrm{~km}$ and $10 \mathrm{~W} / \mathrm{m}^{2}$ at the surface for a $10^{\circ} \mathrm{K}$ temperature difference between the atmosphere and the probe $w$ : dow.

For the discussions to follow, it is :sumed that the true LIR fluxes above 15 ... are approximated by the range of correc: values shown in Fig. 1.

\section{RADIATIVE TRANSFER MODEL RESUL],}

Comparisons of corrected net flux me a surements with calculated fluxes are pie sented in this section: the implication $f$, cloud structure, water vapor distributic . and radiative cooling are discussed in ti: following sections. The new aspects of the models used here are that sounder prolte (LIR) models are included and that indivi:y. ual cloud models based on the Pioneer $V$ : nus nephelometer measurements (Rage. 11 and Blamont, 1980) are applied for each if the probes. Also, the temperature profil s specific to each probe are applied using ti e measurements of Seiff et al. (1980).

\section{a. The Model}

The radiative transfer model makes $u=$ of the basic technique of Pollack (1969), $z$; though the specific implementation diffe considerably. The gaseous opacity mode: $s$ have 48 spectral intervals extending fro 2.09 to $400 \mu \mathrm{m}$ and are based on modil coefficients for $\mathrm{CO}_{2}, \mathrm{H}_{2} \mathrm{O}$, and $\mathrm{SO}_{2}$ from . Pollack and O. B. Toon (1981, person:1 communication). The coefficients were of tained from fits to experimental transmi tances (Pollack et al., 1980). According t, Pollack (1984, personal communication) th: fits are accurate to about $10 \%$ and extrapc lations to higher temperatures are accurat to about $25 \%$ up to $150^{\circ} \mathrm{C}$, with somewh. larger uncertainties at higher temperatures The corresponding uncertainty in calcu lated net flux profiles is $10 \%$ near $55 \mathrm{kr}$ where the atmosphere is near room temper ature and less than $25 \%$ down to $39 \mathrm{~km}$.

The gaseous abundances of $\mathrm{H}_{2} \mathrm{O}$ and $\mathrm{SO}$ assumed for this paper are compared to $\mathrm{Pi}$ oneer Venus and Venera measurements it Fig. 2. Six water vapor distributions art shown with one approximating the Vener: 
$11 / 12$ spectrophotometer results (Moroz et al., 1980), one approximating the Pioneer Venus gas chromatograph (LGC) results (Oyama et al., 1980), and four with constant mixing ratios from the surface to various altitudes in the clouds. The smoothness of the profiles is probably idealistic, espe- cially in regions where the atmosphere is statically stable, but higher vertical resolution is not available. The average level of the net flux at most altitudes in and below the clouds is significantly affected by water vapor, and sudden large changes of the mixing ratio with altitude would introduce

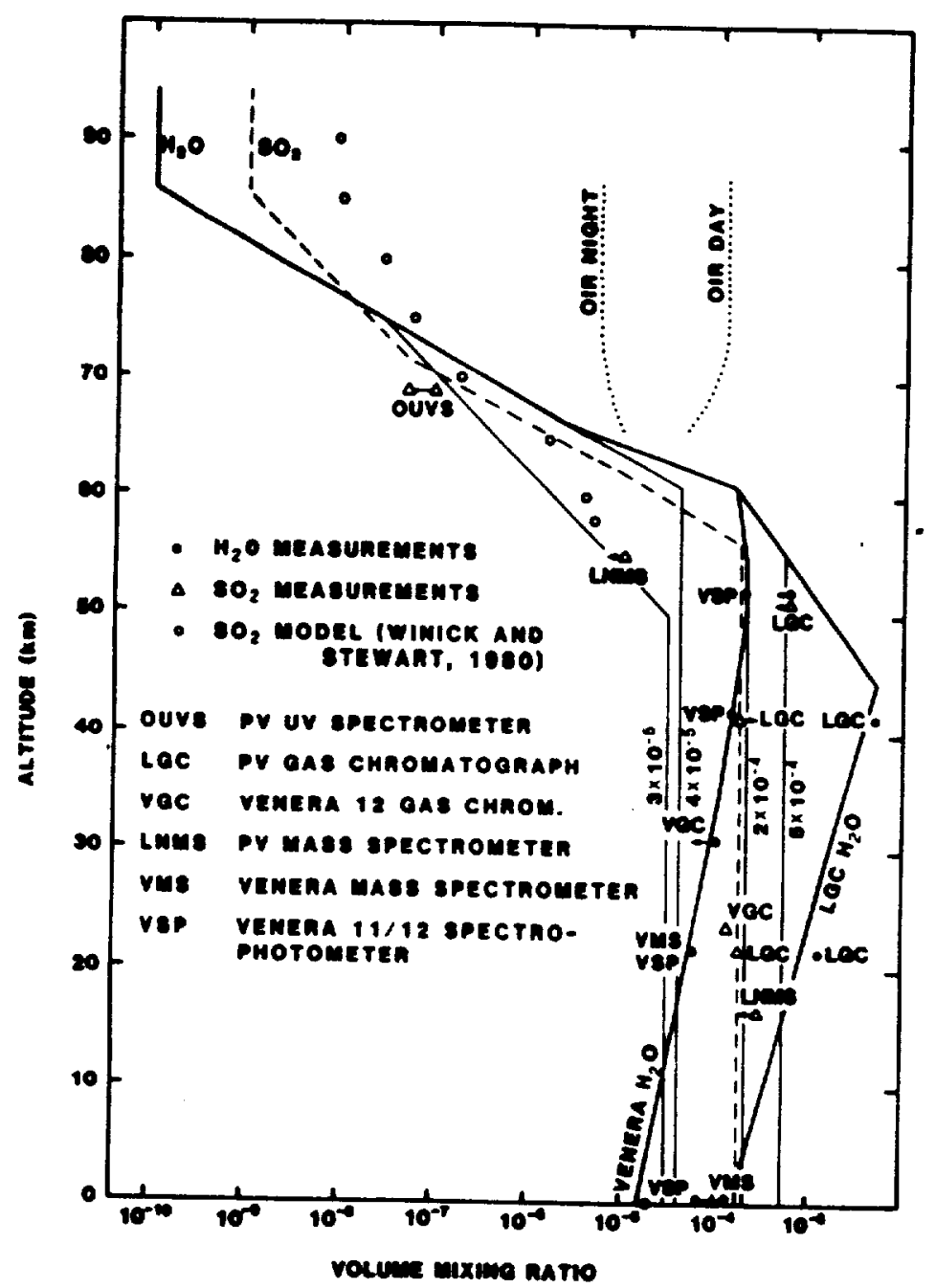

Fic. 2. Gas abundapce models for rediative transfer calculations of net Aux compared to measurements (von Zame et al., 1933). The dached curve is the assumed $\mathrm{SO}_{2}$ distribution. The six solid curves sre the water vapor distributions used. The four with constant water vapor mixing ratios below $50 \mathrm{~km}$ are labeled with that mixing ratio. The profle labeled Venera $\mathrm{H}_{2} \mathrm{O}$ approximates Vener $11 / 12$ spectrophotometer measuremeats (Moroz et al., 1990) and the proble labeled LGC approximates the Pioneer Veaus gas chromatognpt resuhs (Oyama ef al., 1920). The water vapor profiles retrieved from the Pioneer Venus ortiter intrared rediometer (Schofield ef al., 1932) are also shown above the clouds. The difference of these proales from the model profiles does not effect the results presented at the altitudes of the probe meanurements. 
structure in the net flux profile (Suomi $e t$ al., 1980). The water vapor mixing ratios retrieved by the orbiter infrared radiometer (OIR) above the clouds (Schofield et al., 1982) are considerably larger than those assumed here, but the significant differences occur at altitudes that are too high to influence the probe flux calculations. The effect of $\mathrm{SO}_{2}$ on the thermal net flux is significantly smaller than that of water vapor and measurements of $\mathrm{SO}_{2}$ are more consistent. Therefore, only one $\mathrm{SO}_{2}$ distribution is used for all the calculations presented here.

All cloud particles are assumed to be $75 \%$ sulfuric acid. The infrared opacities are derived from single particle absorption coeffcients based on Mie scattering calculations using the imaginary refractive indices of Palmer and Williams (1975). Our representation of the sounder probe cloud measured by the Pioneer Venus cloud particle spec- trometer (LCPS) (Knollenberg and Hunte 1980 ) is illustrated in Fig. 3. Below 64 km, t is essentially the same as the representatic $n$ of the LCPS measurements used by $T$ :masko et al. (1980a). The visible optic it depths and the implied number densities $f$ i each of the four particle size distributio.s are summarized in Table $I$. The numb r densities are included to ease compariso $s$ with other models, but it should be remer :bered that extinction coefficients are mur $h$ better defined by the LCPS measuremen $s$ than number densities (Knollenberg an $d$ Hunten, 1980; Knollenberg, 1984). [No e also that the mode 3 number densities $f$ if the log-normal representations of $t \mathrm{e}$ LCPS data in Table 4 of Knollenberg ard Hunten (1980) are too large by a factor if $2 \sigma_{g}$ (Knollenberg, 1981, personal commur: cation).] There is a large uncertainty in $\mathrm{tl}$ ? mode 1 number density, because the pe: $k$

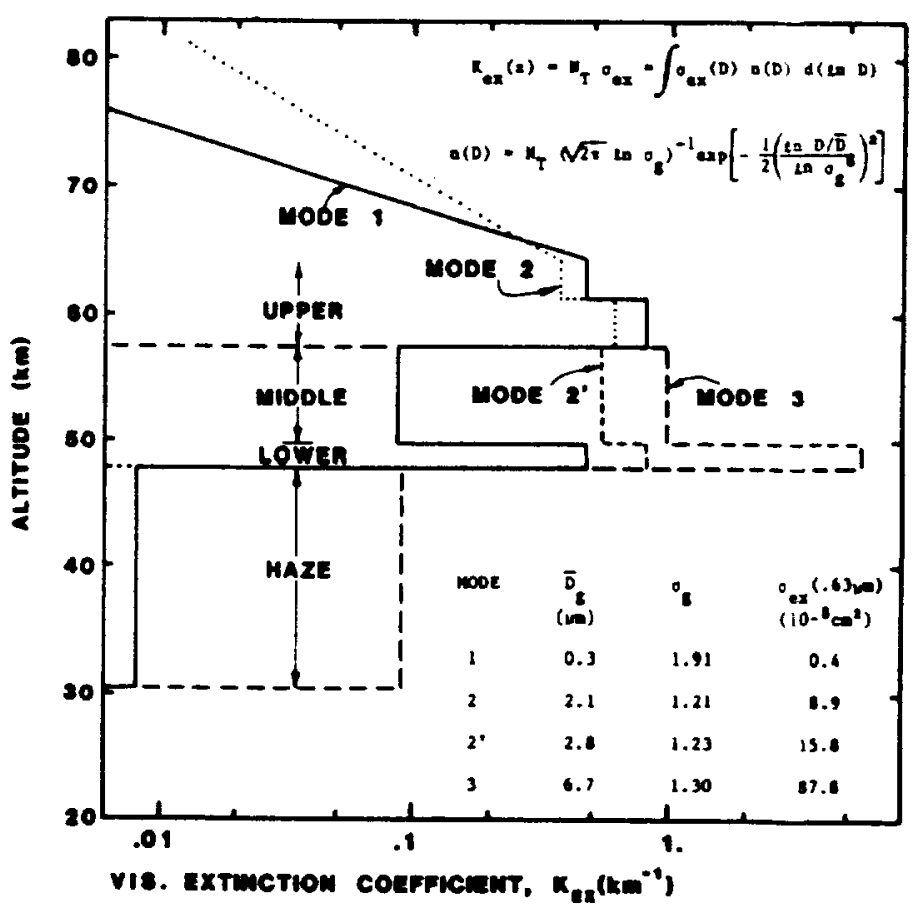

FIc. 3. Cloud model for radiative transfer calculations of sounder probe net tux. The model is essentially the same as that used by Tomasko et al. (1980) and approximates the Pioneer Venus LCPS measurements (Knollenberg and Hunten, 1990). All of the cloud particles are assumed to be 75\% sulfuric acid and are separated into four modes, with stightly different size distributions being used for mode 2 in the upper and the middle clouds. 
TABLE I

Sounder Phome Cloud Model

\begin{tabular}{|c|c|c|c|c|c|c|}
\hline Cloud & Mode & $\underset{(\mathrm{km})}{\Delta \boldsymbol{Z}}$ & $\underset{(a t m)}{\Delta P}$ & $\begin{array}{l}\text { No. density } \\
\left(\mathrm{cm}^{-3}\right)\end{array}$ & $\begin{array}{c}0.63 \mu \mathrm{m} \text { extinct. coefr. } \\
\left(\mathrm{km}^{-1}\right)\end{array}$ & Optical depth \\
\hline Upper & $\begin{array}{l}1 \\
2\end{array}$ & $>64.3$ & $<0.101$ & $\frac{-}{-}$ & $\overline{-}$ & $\begin{array}{l}1.20 \\
1.80\end{array}$ \\
\hline Upper & $\begin{array}{l}1 \\
2\end{array}$ & $61.3-64.3$ & $0.166-0.101$ & $\begin{array}{r}1155 \\
41\end{array}$ & $\begin{array}{l}0.462 \\
0.367\end{array}$ & $\begin{array}{l}1.40 \\
1.10\end{array}$ \\
\hline Upper & $\begin{array}{l}1 \\
2\end{array}$ & $57.5-61.3$ & $0.318-0.166$ & $\begin{array}{r}1954 \\
68\end{array}$ & $\begin{array}{l}0.789 \\
0.605\end{array}$ & $\begin{array}{l}3.00 \\
2.30\end{array}$ \\
\hline Middle & $\begin{array}{l}1 \\
2 \\
3\end{array}$ & $49.7-57.5$ & $1.013-0.318$ & $\begin{array}{r}213 \\
34\end{array}$ & $\begin{array}{l}0.006 \\
0.541\end{array}$ & $\begin{array}{l}0.67 \\
4.22\end{array}$ \\
\hline Lower & $\begin{array}{l}3 \\
1 \\
2 \\
3\end{array}$ & $47.9-49.7$ & $1.27-1.013$ & $\begin{array}{r}11 \\
1169 \\
51 \\
64\end{array}$ & $\begin{array}{l}0.955 \\
0.472 \\
0.800 \\
5.640\end{array}$ & $\begin{array}{r}7.45 \\
0.85 \\
1.44 \\
10.15\end{array}$ \\
\hline
\end{tabular}

of the distribution is at smaller sizes than the smallest sizes measured. However, mode 1 has little effect on infrared calculations unless the number densities are much higher than those measured or unless mode 1 is significantly more absorbing in the infrared than sulfuric acid. The present conflict over the existence of mode 3 and the number densities of large particles (Toon et al., 1984; Knollenberg. 1984) is discussed in Section 4.

Cloud representations for the day, night, and north probes are obtained by scaling the sounder probe model using nephelometer backscatter measurements (no direct particle size measurements were made at the small probe sites). It is assumed that the same particle modes observed by the sounder probe were present at the other sites and that inside each of the three major cloud layers (upper, middle, and lower) the modes occurred in the same ratio. Then the ratio of nephelometer backscatter measurements at a small probe site to that at the sounder probe site in the same cloud layer defines the number densities for each small probe cloud. For example, the ratio of the nephelometer measurements in the middle cloud of the night probe to that for the sounder probe is about 1.15. Therefore, number densities of 39 and $12.5 \mathrm{~cm}^{-3}$ were used to represent the middle cloud modes $2^{\prime}$ and 3, compared to 34 and $11 \mathrm{~cm}^{-3}$ for the sounder probe. For the upper cloud in the sounder model, which is represented by different number densities for the layers between 57.5 and $61.3 \mathrm{~km}\left(68 \mathrm{~cm}^{-3}\right)$ and between 61.3 and $64.3 \mathrm{~km}\left(41 \mathrm{~cm}^{-3}\right)$, the larger value was used.

This procedure for generating standard models for each entry probe is not completely internally consistent, assuming all of the particles are sulfuric acid with a refractive index near 1.43. However, we use this standard model, because it is based on a reasonable representation of LCPS data and serves as a useful point of reference with visible flux models (Tomasko et al. 1980a). For the standard sounder cloud model and the nephelometer measurements to be consistent, a refractive index of about 1.5 is required in the upper cloud (Toon et al., 1984) and an index of about 1.35 is required in the lower cloud, while an index of about 1.43 is reasonable in the middle cloud. Consistency with an index of 1.43 throughout the clouds requires that the number densities of mode 3 in the lower cloud be reduced by a factor of about 2 (Esposito et al., 1983) and that the amount of mode 2 in the upper cloud be increased by about 3. 


\section{b. Modeled Net Fluxes}

The dominant model variables, which can affect calculated fluxes significantly and which are not tightly constrained by other measurements, are the water vapor mixing ratio, the mode 3 number densities in the middle and lower clouds, and the mode 2 number density in the upper cloud. The number density variables are factors by which the number density profiles (determined from nephelometer backscatter) are multiplied. The physical property of the clouds corresponding to these factors may not be number density. These variables are used to indicate whether the measurements favor a larger or smaller cloud extinction than that modeled, but the source of any difference could be cloud particle composition, phase, or number density; it could even be gaseous.

The water vapor mixing ratio is the factor which determines the level of the net flux below the clouds. Sulfur dioxide is the only other known absorber with a significant concentration, and at the level indicated by current measurements it is considerably less absorbing than water vapor. The water vapor profile can also have a significant influence on the modeled fluxes in the clouds, but its effect is expected to be secondary to that of the cloud properties, especially in the upper cloud (where its saturation concentration over sulfuric acid is not large enough for it to have a dominant effect). We did not attempt to refine the model fits to the data by adjusting the water vapor profiles in the clouds, and, as mentioned earlier, we confined the water vapor profiles to measured data or to profiles with constant mixing ratios over most of the modeled altitude range.

Figures 4-7 compare calculated net flux profiles to the corrected measurements for the sounder, day, night, and north probes, respectively. The figure legends give the factors by which the number densities for modes 2 and 3 are multiplied for each profile shown. Also shown are the representa- tions of the nephelometer backscatter me :surements used for the cloud models. Tle definition of the upper, middle, and low. I clouds used here are the same as those $a$. signed in Knollenberg and Hunten (198C, the boundaries are marked by substanti dips or changes in the backscatter profil. s shown in the figures.

The basic approach for finding appros : mate fits to the measured profiles was 0 select a water vapor profile which givis

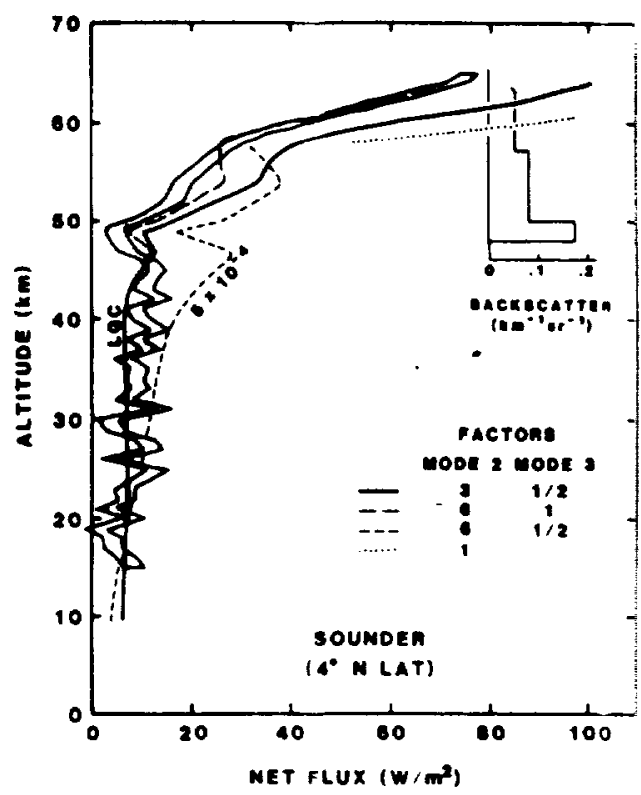

FIG. 4. Sounder probe corrected net nuxes con pared to radiative transfer profiles for different clou models and water vapor profiles. The corrected tuxt are assumed to lie in the range of the correctior shown in Fig. 1 for an obstruction temperature ba tween 280 and $300 \%$, although significant deviatior can not be precluded at altitudes where the correctic is large. The amounts of mode 2 and mode 3 particle for the model profiles differ from the standard modt based on LCPS measurements by the multiplicati factors indicated. Mode 2 variations affect the opacit of the upper cloud in the model and mode 3 variation affect the middle and lower clouds. The insert show the representation of the Pioneer Venus nepbelomett measurements (Ragent and Blamont, 1980) used construct the cloud models for the day, night, an north probes. The model profiles are all for the LG: water vapor profile of Fig. 2, except the dashed profil babeled $5 \times 10^{-4}$ to identify the water vapor profil from Fig. 2. 


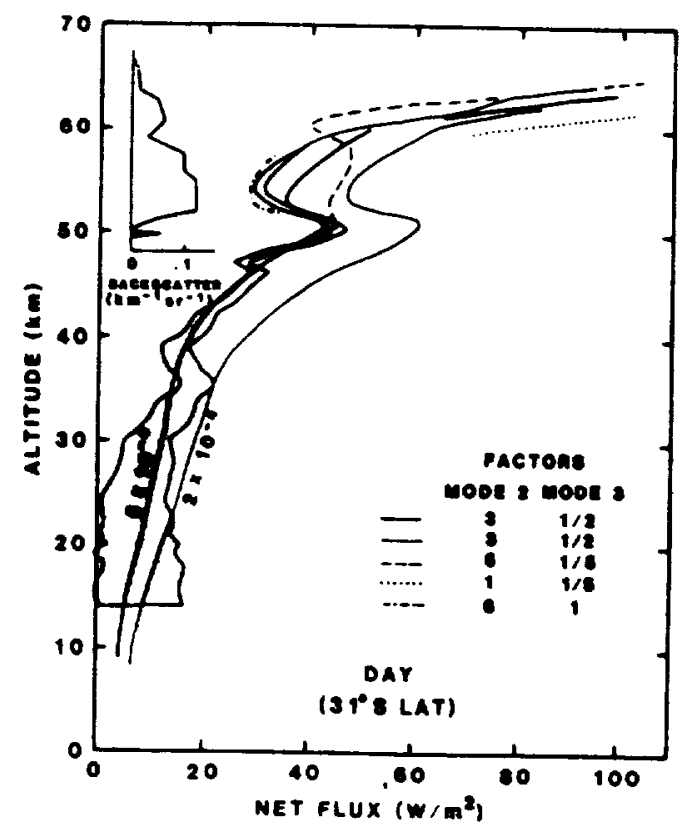

FiG. S. Day probe corrected net fluxes compared to radiative transfer profiles for different cloud models and water vapor profiles. The corrected luxes are from bounds derived in Revercomb et al. (1982). The day probe thermal net fluxes have an additional uncertainty from the uncertainty in the solar net fux at its location. The model fit for a water vapor mixing ratio of $2 \times 10^{-4}$ is included to indicate that, if the solar fux were 50 to $70 \%$ larger than that scaled from the measurements at the sounder site. the day probe net fuxes would be comparable to those of the night probe (Fig. 6). All other model profiles are for the water vapor profile identified by a mixing ratio of $5 \times 10^{-4}$ in Fig. 2 . The standard cloud model was scaled from that for the sounder probe using nephelometer measurements as explained in the text. The mode 2 and 3 factors have the same meaning as in Fig. 4. The representation of the nephelometer measurements used for the model cloud is shown in the insert. Note that the lower cloud is essentially absent for this probe.

about the right level of flux in the lower atmosphere, and then to adjust the two cloud parameters. As a baseline for intercomparison of the different probe results, the bold solid lines in each figure give the flux profiles for a general cloud model with mode 3 number densities reduced by 2 and mode 2 number densities increased by 3 . This cloud model is similar to the model described in 3a which is approximately internally consistent, but the middle cloud is less opaque. This model would require a refractive index of about 1.5 to give the nephelometer backscatter in the middle cloud. Generally, the fits are quite reasonable, and they give confidence that the corrected measurements are meaningful.

Notice that for the day probe a model profile is included with a water vapor mixing ratio of $2 \times 10^{-4}$, which has significantly larger fluxes than the "measured" profile. This model profile was included because of the uncertainty in the net thermal flux at the day probe site introduced by the uncertainty in the solar net flux. The day probe measurements, unlike any of the others, include a contribution from the solar net flux (see Fig. 1). An estimate of the solar flux contribution scaled from the LSFR measurements at the sounder site was removed to yield the thermal net flux profile used

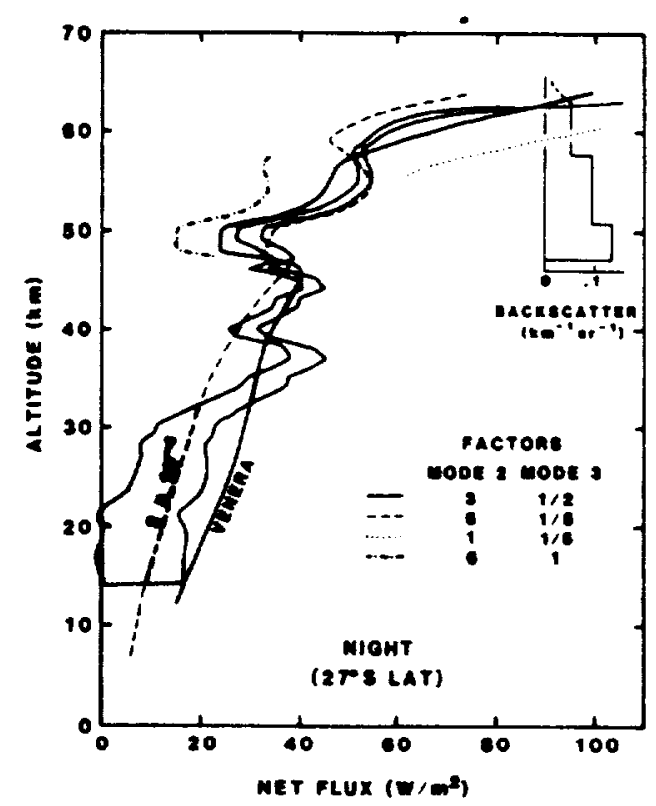

FIG. 6. Night probe corrected net luxes compared to radiative transfer profiles for different cloud models and water vapor profiles. Note the prominent lower cloud, similer to that of the sounder probe. The signifcant suructure in the measured profiles below the clouds occur where the atmospbere is statically stable and may be caused by water vapor byering (Suomi ef al., 1900). The unlabeled model profiles in the cloud region are for the water vapor profile identified by a mixing of $2 \times 10^{-4}$ in Fig. 2. 
here (Suomi et al., 1980). While the solar net flux estimate is consistent with the limited side-looking radiometer measurements made by the nephelometer experiment at the day probe site, considerable deviations are possible. The radiometers did not measure net flux and the calibration uncertainty is $\pm 20 \%$ (Ragent and Blamont, 1980). If the solar net flux were between 50 and $70 \%$ larger than our standard estimate, the SNFR profile would agree quite well with the larger model fluxes and would be in better agreement with the night probe profile measured at about the same latitude.

\section{IMPLICATIONS FOR CLOUD PROPERTIES}

The chemical composition and phase of

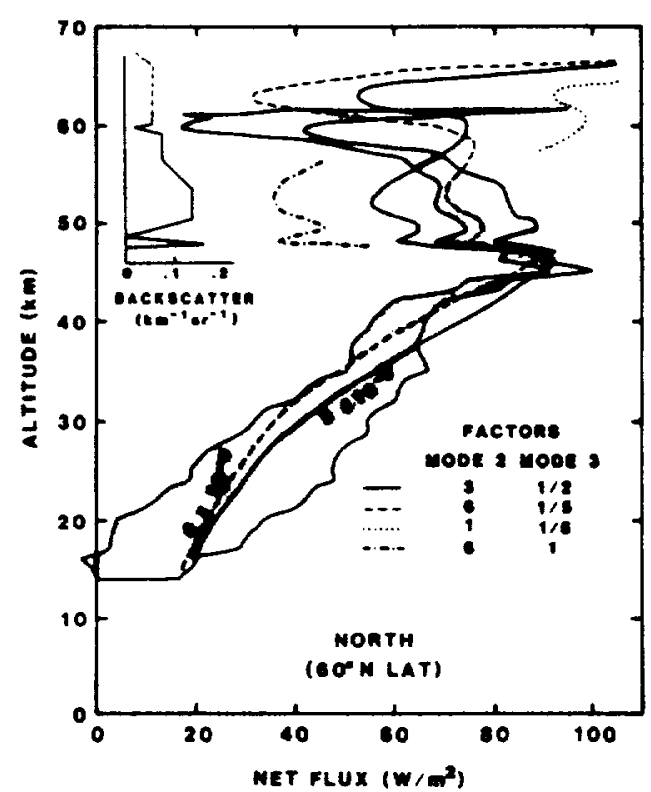

Fig. 7. North probe corrected net fluxes compared to radiative transfer profiles for different cloud models and water vapor profiles. The shading of the measured profile at the highest altitudes shows an estimate of the uncertainty from the deployment transient correction given by $30 \%$ of the low-through correction there. This uncertainty is too small to be noticed for the other small probes. Notice that the tuxes are simificantly bareer for this probe, except near $60 \mathrm{~km}$ where a laree dip occurs. The inability of the models to ft this feature is discussed in Section 4c. The unlabeled model profiles in the cloud region are for the water vapor profile identified by a mixing ratio of $2 \times 10^{-4}$ in Fis. 2 . the cloud particles in the upper cloud and i the large particles (mode 3) observed by th $\mathrm{e}$ Large probe cloud particle spectrometer (LCPS) have not been conclusively settles. Thermal net flux measurements can help 1 : constrain the choices. Previous analyses is dicate that the SNFR flux measuremen: are not consistent with mode 3 or the uppe: cloud particles being pure sulfuric acid, a suming LCPS number densities with no us usual sources of opacity in the upper clou 1 (Suomi et al., 1980). In this section $n$ ? make use of the refined cloud model resul , shown in Figs. 4-7 to give further evidenc: for these conclusions, but we also sho that no reduction of the mode 3 numbr: density is required to model the LIR dat:

\section{a. Cloud Particle Mode 3}

The controversy over the existence if mode 3 has been summarized by Esposit et al. (1983). Basically, there is agreemer t that the large particles detected by LCP; exist, but the number of large particles of served is too large (by factors of betwee: about 2 and 4) to be consistent with coinc:dent nephelometer and solar flux radiom ter (LSFR) results, if the particles are con posed of sulfuric acid. The two primar options for explaining these discrepancif are that (1) the particles are solid, with a 1 unknown composition and undetected pa. ent gas (Knollenberg and Hunten, 1981: Knollenberg, 1984) or (2) the measure I number densities of large particles are tc:? large by about a factor of 4 , and mode 3 ; really the tail of the mode 2 distribution if spherical $\mathrm{H}_{2} \mathrm{SO}_{4}$ particles (Toon et al 1984).

Our present analyses of the IR net flu : measurements do not resolve the contr. versy, but they do provide new constrain: on the infrared absorption characteristics of the clouds which any explanation shoul 1 satisfy. The large mode 3 particles affect th: model results of Figs. 4-7 in the middle an 1 the lower clouds which extend from abol $t$ 57 to $48 \mathrm{~km}$ for the sounder probe, 59 to $\$$ $\mathrm{km}$ for the day probe, 58 to $47 \mathrm{~km}$ for th: 
night probe, and 59 to $48 \mathrm{~km}$ for the north probe. The model results with mode 3 reduced by 2 and mode 2 increased by 3 (solid line) have shapes similar to the measured profiles in these regions for all of the probes. However, getting quantitative agreement requires adjustment of the mode 3 reduction factors for each profile.

It is clear that no single factor for adjusting the mode 3 number density gives an optimum fit to the data for each of the individual probes. Both the sounder and day profiles are fit quite well without any reduction of mode 3, while night and north require a reduction of between 2 and 5 . The sounder model results are slightly larger than the measurements even without reducing mode 3, although the difference can easily be accounted for by the uncertainty in the cloud properties or the water vapor profile. The day probe comparison is unusual because there is essentially no lower cloud. $A$ reduction of the mode 3 in the middle cloud at the day probe site by a factor of 5 is clearly too much, although a factor of 2 is possible, especially given the uncertainty in the solar flux. The night and north SNFR profiles are definitely not consistent with the standard mode 3 amounts and are most consistent with a reduction of about 4 . The reduction factors from the infrared mea- surements might suggest that there is a global dependence of cloud structure on local solar time, with the nightside having a smaller proportion of large particles. However, considering the differences between the cloud structure at the day and sounder sites, the uncertainties inherent in these cloud models, and that a consistent explanation for all of the available data has not been found, such a conclusion is not warranted.

Mode 3 reduction factors deduced from the comparison of Figs. 4-7 are summarized in Table 11 . The numbers given in parentheses are the preferred values. Also shown are the reduction factors deduced from nephelometer measurements based on results presented in Esposito et al. (1983. Table IV) and from the solar flux radiometer measurements (Tomasko et al., 1983) on the sounder probe. The different measurements from the sounder probe are in fair agreement in the middle cloud, where the reduction factors range from 1 to 1.6 , if the refractive index is assumed to be that of sulfuric acid. However, in the lower cloud the infrared measurements favor a factor of 1 , the backscatter measurements favor 2 (with refractive index $=1.43$ ), and the solar measurements favor 3.5. The apparent inconsistency between the LIR infrared mea-

TABLE II

Mode 3 Reduction factons

\begin{tabular}{|c|c|c|c|}
\hline Source & Lower cloud & Middle cloud & Reference \\
\hline \multicolumn{4}{|l|}{ Infrared net flux } \\
\hline Sounder & $1-2(1)$ & $1-2(1)$ & \\
\hline Day & - & $1-2(1.5)$ & \\
\hline Nisht & $2-5(3)$ & $2-5(4)$ & \\
\hline North & $2-5(4)$ & $2-5(5)$ & \\
\hline \multicolumn{4}{|l|}{ Nephelometer } \\
\hline Refractive index $=1.43$ & $2.0^{\circ}$ & $1.2^{4}$ & \\
\hline 1.50 & 3.0 & 1.9 & Esporito ef al.. 1983 \\
\hline $\begin{array}{l}\text { Solar net tux (LSFR) } \\
\text { Particle measurement (LCPS) }\end{array}$ & 3.5 & 1.6 & Tomasko et al., 1983 \\
\hline (acceptable reduction) & $2-2.5$ & $2-2.5$ & Knolleabers, 1984 \\
\hline
\end{tabular}

- Numbers in parentheses are preferred values.

- Sealed from values for ref. index of 1.5 (see Toon et al., 1994). 
surements and the nephelometer measurements is not very strong, because only small changes to the LIR fluxes would make them consistent with a reduction factor of 2. Also, the size of the flux depression in the lower cloud is significantly dependent on the flux level below the clouds, as shown by the model profile for a water vapor mixing ratio of $5 \times 10^{-4}$ and a reduction factor of 2. Considering the uncertainties in the IR measurements, a reduction factor of 2 would seem to give a reasonable explanation for all but the solar flux measurements in the lower cloud and is consistent with Knollenberg's estimate of 2 to 2.5 for the reduction of the extinction from mode 3 which is consistent with plausible uncertainties in the LCPS measurements.

\section{b. The Upper Cloud: Mode 0 and Sulfur}

Several Pioneer Venus measurements made in the upper cloud are not consistent with analyses which assume that the particles in this region are sulfuric acid with number densities from LCPS (Tomasko, 1983). These include the nephelometer and solar flux radiometer (LSFR) measurements in the visible, the LIR and SNFR measurements in the infrared. In addition, the IR emission to space calculated with models which extrapolate the LCPS ratio of the optical depths of modes 1 and 2 to altitudes above the measurements is significantly larger than orbiter infrared radiometer measurements.

The discrepancy between model fluxes and the LIR and the SNFR probe measurements can be seen above 57 to $59 \mathrm{~km}$ in Figs. 4-7. The model results indicated by the heavy solid line in each figure have the mode 2 number density enhanced by a factor of 3 . This model clearly gives a much better fit to the measurements than the model with no mode 2 enhancement, although neither fit is very good for the north probe as is discussed later. The sounder probe measurements actually favor an enhancement factor closer to 6 , and the day and night probes favor a factor between 3 and 6 at most altitudes. As mentioned ea lier, we are not suggesting that the number densities of mode 2 are necessarily thi 1 large, but use number density to indica: the required enhancement in IR extinctior . In the IR, the atmosphere is sufficientl : opaque, even at these altitudes, that a loc. I source of opacity is needed to explain th: difference. Putting more mode 2 in the model clouds above $64 \mathrm{~km}$, as suggested $t$ : Tomasko (1983) to reduce the outgoing flu : to agree with OIR measurements, woul not give agreement with LIR or SNFR.

Enhancement of the opacity of the uppe cloud in the altitude region required to ex plain the probe measurements is supporte by OIR retrievals. The retrievals derive tw parameters of a simple cloud model, in ac dition to temperature and water vapor pro files. The optical depth is assumed to fall of: exponentially with $\log _{e}(P)$, with a scal height which is a factor $f$ times the gas scal height. Explicitly, the optical depth at 11. $\mu \mathrm{m}$ is written as $\delta(P)=\left(P / P_{1}\right)^{1 / f}$, where is the pressure and $P_{1}$ is the pressure at $\mathrm{a}_{i}$ optical depth of one. The retrieved value $c_{\text {. }}$ $P_{1}$ is 100 mbar (or about $64.5 \mathrm{~km}$ altitude and of $f$ is 0.85 , for latitudes below 60 (Schofield and Taylor, 1983). The extinc tion coefficient corresponding to these pa rameters is about 3 to 4 times that from th model of the LCPS measurements use. here. It is also interesting to note that thi simple cloud model is approximately con sistent with the number density of $30 \mathrm{~cm}^{-}$ for mode 2 particles at 28 mbar (about 7 $\mathrm{km}$ ) deduced from Pioneer Venus polarime try (Kawabata et al., 1980).

The existence of a small particle mod (mode 0) was proposed by Suomi et at (1980) to explain the discrepancy in the in frared measurements, without creating as inconsistency with visible experiments Mode 0 is a mode of particles which ar sufficiently small that their scattering cros section is small in the visible as well as is the IR, but which have an imaginary refrac tive index which is large in the IR and smal in the visible (like sulfuric acid). Accordin! 
to Esposito et al. (1983), a problem with the concept of mode 0 is that the required number density is so high that coagulation would create detectable larger particles. They favor a gaseous source of IR opacity.

One solution to the inconsistencies in the visible data is to assume that the upper cloud contains sulfur (Toon et al., 1984; Tomasko, 1983). Sulfur has a larger refractive index which could account for larger backscatter and visible optical depths, and would be consistent with the sugrestion of Toon et al. (1982) that amorphous sulfur is the ultraviolet absorber. Unfortunately, sulfur is transparent in the infrared and, therefore, could not provide the additional IR opacity implied by LIR and SNFR.

In summary, LIR and SNFR measurements imply that there is a missing piece to the puzzle of the upper cloud. A source of infrared opacity is needed in the upper cloud: mode 0 or a gaseous absorber has been suggested.

\section{c. The North Probe Upper Cloud}

While the model profiles in the clouds generally show similar structure to the measured profiles, the agreement breaks down in the upper cloud for the north probe (Fig. 7). The minimum in the measurements near $60 \mathrm{~km}$ occurs near $63 \mathrm{~km}$ in the model and is peculiar because it correlates with a local minimum in the measured cloud backscatter. For the model, the minimum is caused by an inversion in the model temperature profile with a tropopause near $63 \mathrm{~km}$. The existence of an inversion in this region is consistent with radio-occultation measurements at similar latitudes (Kliore and Patel, 1982) and is not inconsistent with probe measurements. No measurements were made between $65 \mathrm{~km}$, where accelerometer data ended, and $61.28 \mathrm{~km}$, where direct in situ temperature measurements began (Seiff et al., 1980). However, $63 \mathrm{~km}$ is about as low as the inversion can reasonably occur based on probe temperature measurements, unless severe local vertical temperature gradients are allowed. The un- certainties in the SNFR measurements at altitudes immediately following deployment are larger for the north probe than for the other probes (Suomi et al.. 1980) but. assuming an uncertainty of $30 \%$ in the deployment transient flow-through error correction as shown in Fig. 7, does not significantly alter the discrepancy. A region of high opacity in the infrared near $60 \mathrm{~km}$ is a possible explanation which may be reasonable in light of the enhanced IR opacity required to explain the other probe measurements.

5. IMPLICATIONS FOR THE GLOBAL DISTRIBUTION OF WATER VAPOR AND RADIATIVE COOLING

All of the profiles of thermal net flux estimated from Pioneer Venus measurements are compared in Fig. 8. Note that the major differences among the profiles are considerably larger than the uncertainties in the corrections caused by the uncertainty in the net flux at $14 \mathrm{~km}$. If the corrections in the deep atmosphere are assumed to be reasonable, and we think they are, a pronounced increase of net flux with latitude is suggested. At most altitudes, the fluxes for the north probe at $60^{\circ} \mathrm{N}$ are clearly the largest, the day and night probe fluxes at about $30^{\circ} S$ are intermediate, and the sounder probe fluxes at $4 \mathrm{~N}$ are smaller. Contemplating the possibility of a global scale latitude de. pendence based on only four probe profiles makes sense for Venus because of the strong zonal organization of the circulation at essentially all altitudes (Counselman et al., 1980) and the zonal symmetry of the Pioneer Venus temperature measurements (Seiff et al., 1980; Kliore and Patel, 1982).

Radiative transfer results for several wa. ter vapor distributions are also shown below the clouds in Fig. 8. The dashed curves have constan mixing ratios below the clouds. The model comparisons clearly suggest that the lower atmosphere at high latitudes is simificantly dryer than at lower latitudes. The water vapor mixing ratio 


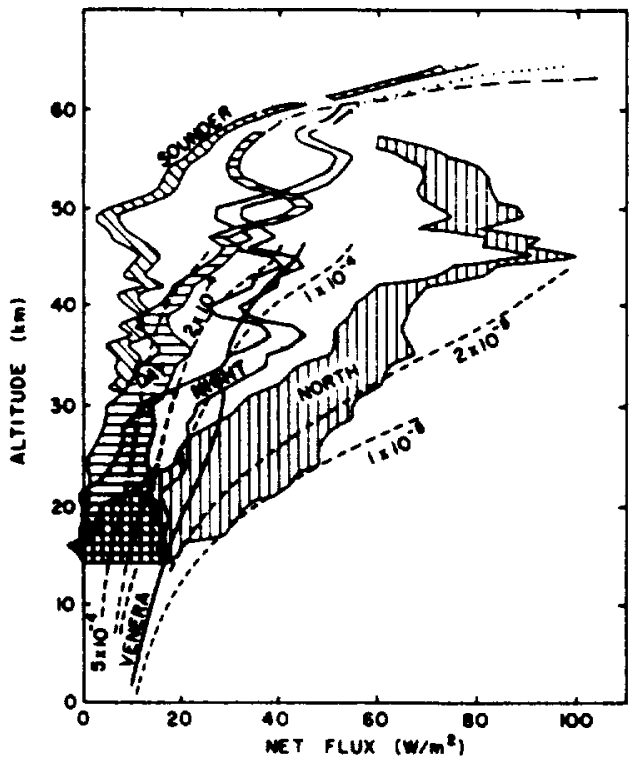

Fig. 8. Comparison of corrected thermal net fluxes from all four Pioneer Venus probes. A range of fuxes is shown for each profile to indicate the expected uncertainty. Flux profiles calculated for the water vapor profiles of Fig. 2 are also shown below the clouds for comparison. The calculated fluxes for water vapor profiles which are constant below $50 \mathrm{~km}$ are shown as dashed and labeled with the water vapor mixing ratio: the one solid line is for the Venera $\mathrm{H}_{2} \mathrm{O}$ profile of Fig. 2.

model which approximately matches the north probe fluxes is about an order of magnitude smaller than that for the night and day probes. The water vapor mixing ratios implied by the net fluxes are approximately as follows: $2-5 \times 10^{-5}$ for north at $60^{\circ} \mathrm{N}, 2-$ $5 \times 10^{-4}$ for day and night near $30^{\circ} \mathrm{S}$ (with day at the wet extreme and night at the dry), and $>5 \times 10^{-4}$ for sounder at $4^{\circ} \mathrm{N}$. The water vapor mixing ratios implied by the LIR fluxes are approximately consistent with the gas chromatograph (LGC) measurements made on the same probe (Fig. 4), but are considerably larger than the Venera $11 / 12$ spectrophotometer measurements made near $10^{\circ} \mathrm{S}$. This suggests that the water vapor distribution at low latitudes may be variable. There were no direct water vapor measurements made on the small probes.
A global distribution of water vapor, wi i relatively wet low latitudes and dry high la . itudes, as suggested by the thermal n: fluxes from Pioneer Venus, could have si nificant implications for understanding th: global circulation. The resulting latitudin I gradient of radiative cooling below th clouds would augment the solar drive $f_{c} r$ the circulation. Thermal net fluxes are con. pared to zonal average solar net fluxt; (shown as dashed lines) in Fig. 9. The soli. $r$ net flaxes indicate the effective latitudin 1 variation of solar radiation available 0 drive the circulation. Zonal average sol: $r$ fluxes are used for comparison because $d$ :urnal variations are expected to be sme: below the clouds (Stone, 1975). The zon 4 average solar net fluxes were derived fro a the Pioneer Venus nominal global averay 2 profile (Tomasko et al., 1980a) with the a .

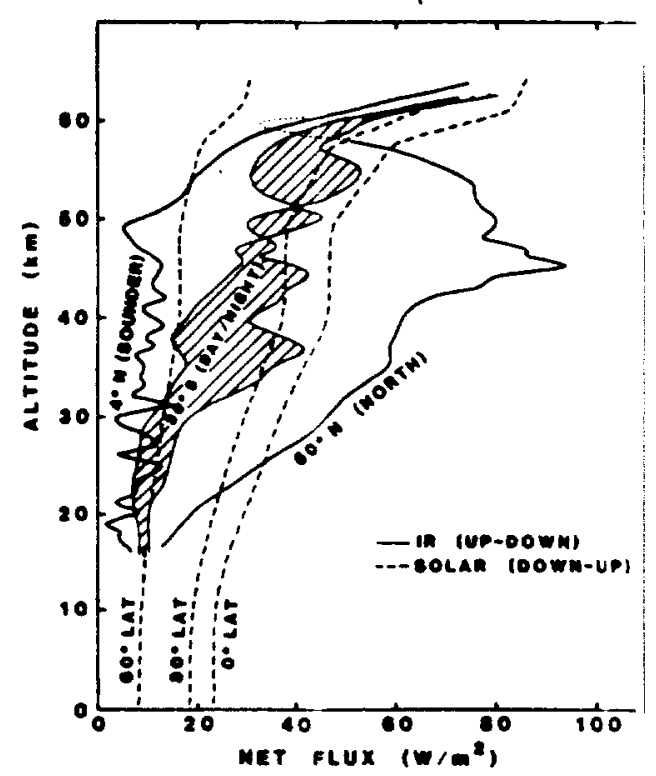

Fic. 9. Thermal net fux estimates for 4,30, and $t$ latitude compared to zonal average solar net fluxes $t$. 0,30 , and $60^{\circ}$ latitude. Note that the thermal and tite solur aet tuxes are defined with different aign conve : tions, such that an increasins net lux with altitu ic indicates beating for the solar protiles and cooling $f$ or the thermol prodies. The zonal average solar net flux :s are based on the Pioneer Venus "nominal" profile a :d the solur zenith ande dependence for the lower atn s sphere calculuted by Tomasko et al. (19906). 
sumption that the solar net fluxes at any given altitude below $57 \mathrm{~km}$ obey the same model for solar zenith angle dependence derived by Tomasko et al. (1980b). The solar net flux is defined to be the downward flux minus the upward flux, opposite to the convention for thermal net flux. Therefore, an increase of solar net flux with altitude indicates heating, while an increase of thermal net flux indicates cooling.

Figure 9 shows that the primary altitudes of solar heating are in the upper and middle clouds, between 10 and $40 \mathrm{~km}$, and at the surface. The region where both the heating and cooling are consistently the largest are above the measurements which began near $64 \mathrm{~km}$ (the mean net flux above the atmosphere is about $157 \mathrm{~W} / \mathrm{m}^{2}$ according to Schofield and Taylor, 1982). However, only a very small fraction of the total atmospheric mass occurs in the upper cloud above $64 \mathrm{~km}$. The momentum and angular momentum of the atmosphere are biggest deep in the atmosphere (between 20 and 30 km; Schubert et al., 1980) and it seems plausible that the direct heating and cooling in the lower atmosphere may provide the drive for a significant part of the atmosphere. The latitudinal gradient of IR cooling below the clouds deduced from the probe measurements is even larger than the latitudinal gradient of solar heating at the same altitudes. In the region below the clouds and above $15 \mathrm{~km}$, the IR cooling at $60^{\circ}$ is considerably larger than the zonal average solar heating at the equator. Also, the IR cooling near the equator appears to be quite small, approximately comparable to the solar heating at $60^{\circ}$. Therefore, the thermal net flux measurements suggest that IR radiative transfer below the clouds is responsible for a substantial part of the equator-to-pole temperature gradient.

It is not clear whether this picture of a zonally symmetric, latitude-dependent water vapor distribution in the lower atmosphere is consistent with chemical models of the atmosphere. However, if a distribution of this type exists, it probably has im- portant consequences for the circulation and may be the missing link in explaining the atmospheric superrotation. The associated IR cooling at hich latitudes would promote descending motions there and might help provide the return flow for a polar vortex circulation (Suomi and Limaye, 1978).

\section{SUMMARY}

Estimates of the true atmospheric net fluxes at the four Pioneer Venus entry sites are presented. The required corrections of the measured fluxes are relatively small in the clouds, but are generally large deep in the atmosphere. The correction procedure for both the small (SNFR) and large probe (LIR) fluxes used model results near $14 \mathrm{~km}$ to establish the size of the correction. The net flux at this altitude is constrained to be fairly small (probably $<16 \mathrm{~W} / \mathrm{m}^{2}$ ), because of the large opacity of $\mathrm{CO}_{2}$.

The primary conclusions drawn from the net flux estimates are as follows:

(i) Thermal net thuxes imply that, on the average, the contribution of mode 3 particles to the IR opacity of the middle and lower clouds is smaller than that indicated by LCPS measurements at the sounder probe site, if the particles are assumed to be sulfuric acid. However, the corrected LIR measurements of net flux at the sounder probe site are most consistent with no reduction of mode 3 from the LCPS measurements, and the day probe results favor a reduction of only about 50\%. A two times reduction is also within reasonable uncertainties for both of these probes, and substantially larger reduction factors of between 2 and 5 are implied for the night and north probe results.

(2) The fluxes at all sites imply that a yet undetermined source of considerable opacity is present in the upper cloud. A mode of very small particles (mode 0 ) or a gaseous absorber are possibilities. Apparently nephelometer and solar flux measurements in the upper cloud sumest the presence of a material with a refractive index near 1.9 . If 
this material is sulfur, it could not explain the thermal net fluxes because its absorption in the thermal IR is too weak.

(3) Beneath the clouds, the thermal net fluxes generally increase with increasing latitude. The water vapor mixing ratios suggested by the fluxes are $2-5 \times 10^{-5}$ at $60^{\circ} \mathrm{N}$, $2-5 \times 10^{-4}$ near $30^{\circ} \mathrm{S}$, and $>5 \times 10^{-4}$ at $4^{\circ} \mathrm{N}$. The water vapor profile implied by the large probe (LIR) fluxes is roughly consistent with the gas chromatograph measurements made on the same probe. A possible interpretation of pattern followed by the four net flux profiles is that it is a global pattern, with less water vapor and more IR cooling below the clouds at higher latitudes.

The last conclusion could be important for understanding the global superrotation. The variation of cooling with latitude implied by the flux profiles appears to be as strong or stronger than the variation of solar heating, suggesting that it plays an important role in determining the pole-toequator temperature gradient and the strength of the general circulation. Enhanced IR cooling below the clouds at high latitudes would tend to promote descending flow at high latitudes, which would be consistent with a general circulation consisting of a polar vortex in each hemisphere.

\section{ACKNOWLEDGMENTS}

We thank G. M. Keating, A. J. Kliore, and V. I. Moroz, the convenors of the Workshop on the Venus International Reference Atmosphere, for providing the incentive to begin this work. We also thank T. Wendricks for drafting the figures appearing in this paper. The work was jointly supported by NASA Grant NGR 50-002-189 under the Planetary Atmospheres Program and Grant NAG 2-266 under the Pioneer Venus Guest Investigator Program.

\section{REFERENCES}

Boese, R. W., R. J. Twarowstu, J. GLLand, R. E. HAssig, AND F. G. Bnown (1990). The infrared radiometer on the sounder probe of the Pioneer Venus mission. IEEE Trans. Geosci. Rem. Sens. GE-18. pp. $97-100$.

Counselman, C. C., III, S. A. Gounevttch, R. W.
King, G. B. LoRiot. And E. S. Ginsberg (19;) Zonal and meridional circulation of the lower ats is: sphere of Venus determined by radio interferol ie try. J. Geophys. Res. 85, 8026-8030.

Esmosito. L. W.. R. G. KMOLlenderg, M Marov, O. B. ToON, AND R. P. Tunco (1983). in clouds and hazes of Veaus. In Venus (D. $M$. $H$ : ten, L. Colin, T. M. Donahue, and V. I. Mor.: Eds.), pp. 484-564. Univ. of Arizona Ptess, Tucs :

Kawabata, K., D. L. Coffeen, J. E. Hansen, A A. LANe, M. SATo, And L. D. Travis (1980). Cl u and baze properties from Pioneer Venus polari te try. J. Geophys. Res. 85, 8129-8140.

Klione, A. J., AND I. R. PAtel (1982). Thermal sti : ture of the atmosphere of Venus from the Pior :s Venus radio occultations. Icarus 52, 320-334.

KNOLLENEERG, R. G. (1984). A reexamination of i evidence of large, solid particles in the cloud: Venus. Icarus 57, 161-183.

Knollenserg, R. G., AND D. M. Hunten 19 The microphysics of the clouds of Venus: Result the Pioneer Venus particle size spectrometer exf i ment. J. Geophys. Res. 85, 8039-8058.

Moroz, V. I., Yu. M. Golovin, A. P. Exonomor I E. Moshian, N. A. Pakfent'ev. and N. 1 SAN Ko (1980). Spectrum of the Venus day sky. is iure 244, 243-244.

Oyama, V. I., G. C. Carle, F. Woeller, J. B. I : lack, R. T. Reynolds, and R. A. Craig 190 Pioneer Venus gas chromatography of the lowe: a mosphere of Venus. J. Geophys. Res. 85, 7811 7902.

Palmer, K. F., and D. Williams (1975). Op: : constants of sulfuric acid: Applications to the clc " of Venus? Appl. Opt. 14, 208-219.

Pollack. J. B. (1969). Temperature structure of : , gray planetary atmospheres. Icarus $10,301-31$ :

Pollack, J. B., O. B. TOON. ANo R. W. BC (1980). Greenhouse models of Venus' high sur is temperature, as constrained by Pioneer Venus $\mathrm{r}$ a surements. J. Geophys. Res. 85, 8223-8231.

Ragent, B., and J. Blamont (1980). The Struc of the clouds of Venus: Results of the Pioneer $V_{C} 1$ Dephelometer experiment. J. Geophys. Res. 8 8089-8105.

Revercomb, H. E., L. A. SRomovsky, and V . SuOMI (1982). Reassessment of net radiation I = surements in the atmosphere of Venus. Icarus 5 279-300.

SChofield, J. T., AND F. W. TAYLOR (1982). global thermal emission from the Venusian ai in sphere. Icarus 52, 245-262.

SChOfIEld, J. T., AND F. W. TAYLoR (1983). surements of the mean, solar-fixed temperature is cloud structure of the middle atmosphere of Ve iu Q. J. R. Meteorol. Soc. 16, 57-80.

SCHOFIELD, J. T., F. W. TAYLOR, AND D. J. A Cleese (1982). The global distribution of wate: 
por in the middle atmosphere of Venus. Icarus 52. 263-278.

Schunert, G.. C. Covey, A. Del Genio. L. S. Elson, G. Keating. A. Seiff, R. E. Young, J. A.t. C. C. Counselman HI, A. J. Klione, S. S. Limaye, H. E. Revercomb, L. A. SRomovsey, V. E. SUOmi, F. TaYlor, R. WOO, and U. VON Zahn (1990). Structure and circulation of the Venus atmosphere. J. Geophys. Res. 85, 8007-8025.

Seiff A., D. B. Kirx, R. E. Young, R. C. BlanChand, J. T. Findlay, G. M. Kelly, and S. C. SOMMER (1980). Measurements of thermal structure and thermal contrasts in the atmosphere of Venus and related dynamical observations: Results from the four Pioneer Venus probes. J. Geophys. Res. \&s, 7903-7933.

Sromovsty, L. A., H. E. Revencom, AND V. E. Suom (1990). Pioneer Venus small probe net bux rediometer experiment. IEEE Trans. Geosci. Rem. Sens. GE-18, pp. 117-122.

STONE, P. H. (1975). The dynamics of the atmosphere of Venus. J. Almos. Sci. 32, 1005-1016.

Suomi, V. E., ANd S. S. Limaye (1978). Venus: Further evidence of vortex circulation. Science (Washington, D.C.) 201, 1009-1011.

SUOMI, V. E., L. A. Snomovsky, AND H. E. REVERCOMB (1900). Net radiation in the atmosphere of Ve. nus: Measurements and interpretation. J. Geophys. Res. 85, 8200-8218.

Tomasko, M. G. (1983). The thermal balance of the lower atmosphere of Venus. In Venus (D. M. Hunten. L. Colin, T. M. Donahue, and V. I. Moroz.
Eds.), pp. 604-631. Univ. of Arizona Press, Tucson. Tomaszo, M. G., L. R. Docse, AND P. H. SMITH (1903). The struciure of the clouds of Venus and the almospheric heating rate due to the absorption of solar energy. Presented at the Venus International Reference Atmosphere Workshop, Hamburg. Federd Republic of Germany, 24-26 August.

Tomasio, M. G., L. R. Doose, P. H. SMith, and A. P. ODELL (1900). Measurements of the hux of sunlight in the atmosphere of Venus. J. Geophys. Res. 8, 8167-8186.

Tomasko, M. G., P. H. SMrth, V. E. SUOM], L. A. Sromovscy, H. E. Revencome, F. W. TAYLOR. D. J. Mastonchiz, A. Seiff, R. W. Boese, J. B. PolLACE, A. P. Inoersol, G. SChunert, AND C. C. Covey (1900b). The thermal balance of Venus in lipht of the Pioncer Venus mission. J. Geophys. Res. 8, 8187-8199.

Toon, O. B., B. Ragent, D. Colmurn, J. Blamont, AND C. Cot (1984). Lare solid particles in the clouds of Venus: Do they exiat? Icarus 57, 143-160.

Toon, O. B., R. P. Tunco, And J. B. Pollace (1982). The ultriviolet absorber on Venus: Amorphous sulfur. Icarus 51, 358-373.

von Zahn, U., S. Kumar. H. Niemann, and R. Puinn (1983). Composition of the Venus atmosphere. In Venus (D. M. Hunten, C. Colin, T. M. Donahue, and V. I. Moroz, Eds.), Pp. 299-430. Univ. of Arizona Press, Tucson.

Winich, J. R., AND A. I. F. Stewart (1980). Photochemiatry of $\mathrm{SO}_{2}$ in Venus' upper cloud layers. $J$ Geophys. Res. 85, 7849-7878. 